\title{
PILOT-SCALE INVESTIGATION OF PHOSPHORUS REMOVAL FROM SWINE MANURE BY THE MANURE PHOSPHORUS EXTRACTION (MAPHEX) SYSTEM
}

\author{
C. D. Church, S. K. Fishel, M. R. Reiner, P. J.A. Kleinman, A. N. Hristov, R. B. Bryant
}

\begin{abstract}
HighLIGHTS
- Swine manure contains nutrients and organic material that is beneficial to crops.

- Farmers are under increasing pressure and regulation to not apply high phosphorus manure to soils.

- The MAPHEX System removed greater than $96 \%$ of the phosphorus in swine manures.

- Both capital equipment and treatment costs were lower for swine manure than dairy manure.
\end{abstract}

\begin{abstract}
Swine manure is typically in slurry form and contains nitrogen (N), phosphorus $(P)$, and organic material that is beneficial to crops. Unfortunately, for economic and logistical reasons, manure tends to be applied to soils near where it is produced and P concentrations increase to the point that they are often in excess of crop demands. With the implication that runoff of excess $P$ contributes to eutrophication of streams and other water bodies, farmers are experiencing increasing pressures and regulation to not apply manure to those soils. We previously reported on an invention capable of removing $P$ from dairy manures. This pilot-scale study shows that the MAPHEX System can remove greater than $96 \%$ of the phosphorus in swine manures, and strongly suggests that, once scaled up, the essentially $P$ free effluent could be beneficially used for fertigation without further loading the receiving soils with $P$. This scaling up has the potential to reduce storage volumes to allow for mitigation of overflow problems during large storms. Furthermore, this study suggests that capital equipment costs and treatment costs for swine manure would be lower than for treating dairy manure.
\end{abstract}

Keywords. Chemical treatment, Manure, Phosphorus, Solid separation, Swine, Treatment systems. \footnotetext{
(c) (1) (3) () The authors have paid for open access for this article. Attribution-NonCommercial-NoDerivatives 4.0 International License https://creative commons.org/licenses/by-nc-nd/4.0/

Submitted for review in December 2019 as manuscript number NRES 13698; approved for publication as a Research Article by the Natural Resources \& Environmental Systems Community of ASABE in April 2020.

Mention of trade names or commercial products in this publication is solely for the purpose of providing specific information and does not imply recommendation or endorsement by the U.S. Department of Agriculture (USDA). USDA is an equal opportunity provider and employer. The U.S. Department of Agriculture prohibits discrimination in all its programs and activities on the basis of race, color, national origin, age, disability, and where applicable, sex, marital status, familial status, parental status, religion, sexual orientation, genetic information, political beliefs, reprisal, or because all or part of an individual's income is derived from any public assistance program. (Not all prohibited bases apply to all programs.) Persons with disabilities who require alternative means for communication of program information (Braille, large print, audiotape, etc.) should contact USDA's TARGET Center at (202) 720-2600 (voice and TDD). To file a complaint of discrimination, write to USDA, Director, Office of Civil Rights, 1400 Independence Avenue, S.W., Washington, D.C. 20250-9410, or call (800) 795-3272 (voice) or (202) 720-6382 (TDD).

The authors are Clinton D. Church, Environmental Chemist, Sarah K. Fishel, Support Scientist, Michael R. Reiner, Hydrologic Technician, Peter J.A. Kleinman, Soil Scientist, USDA-ARS, University Park, Pennsylvania; Alexander N. Hristov, Professor, Pennsylvania State University, University Park, Pennsylvania; and Ray B. Bryant, Soil Scientist, USDA-ARS, University Park, Pennsylvania. Corrresponding author: Clinton D. Church, 3702 Curtin Road, University Park, PA 16802; phone: 814-863-8760; e-mail: clinton.church@ars.usda.gov.
}

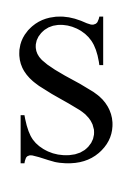
wine manure, like dairy manure, is typically in slurry form and contains nutrients [primarily nitrogen $(\mathrm{N})$ and phosphorus $(\mathrm{P})]$ and organic material that are beneficial to crops. Unfortunately, the concentrations of nutrients in both manures are too low (Pagliari and Labosky, 2012, 2013) to make transportation of bulk manures over large distances economically viable. Furthermore, since it must be transported in tanks, that transportation is inconvenient as well. Therefore, these manures tend to be applied to soils near where they are generated, and, over time, $\mathrm{P}$ concentrations in soils increase to the point that soil $\mathrm{P}$ concentrations are often in excess of crop demands (Sharpley et al., 1994). Furthermore, because of the implication that $\mathrm{P}$ runoff from agricultural operations plays an important part in eutrophication of streams and other water bodies, farmers are experiencing increasing pressures and regulation to not apply animal manures to those soils (Kleinman et al., 2012).

One manure management practice that differs between dairy and swine operations is the tendency for swine manure solids to readily separate from the liquid phase and settle to the bottom of lagoons or storage pits. Many swine farmers take advantage of this characteristic and tend to only land apply the manure liquor on top while letting sludges that settle out accumulate for as much as two to three decades, and 
then deal with those sludges through hauling and disposal (Vansickle, 1999; Chastain and Henry, 2003). This accumulation of sludge results in storage volumes being reduced over time and consequently, there may not be enough excess storage to handle the volume of large storms, and overflow occurs (Fleishman, 2018; Pierre-Louis, 2018; Schlanger, 2018).

We previously reported on an invention that 1) is designed to be a solution to the $\mathrm{P}$ overloading that happens when unnecessary $\mathrm{P}$ is added to agricultural soils (Church et al., 2016, 2017), 2) is scalable such that it can be used as a mobile system, and 3 ) has shown to be capable of removing greater than $90 \%$ of the $\mathrm{P}$ from a wide range of dairy manures (Church et al., 2018) while retaining greater than $90 \%$ of the $\mathrm{N}$ in the final effluent for beneficial use by the farmer (Church et al., 2016, 2017, 2018). The technology has also shown to recover and concentrate alkalinity into a solid form on a farm that used greater amounts of lime during manure handling (Church et al., 2018), remove $50 \%$ of the odor from dairy manure (Church et al., 2018) and to remove greater than $80 \%$ of total coliforms and E. coli (Church et al., 2018). Furthermore, the technology has not shown to alter the $\mathrm{pH}$ of the final effluent respective to raw dairy manure as other treatment technologies can. (Church et al., 2016, 2017, 2018).

While the MAPHEX System was originally designed for dairy manures and tested on dairy manures and acid whey from yogurt processing, we postulated that it was capable of removing $\mathrm{P}$ from other slurries, including swine manure. Thus, our goal was to test the potential of the MAPHEX System to remove $\mathrm{P}$ from swine manures, allowing farmers to increase the storage capacity of lagoons and pits by land applying the resulting effluent without overloading the soils with P. Since we had never tested the system on swine manures previously, this entailed performing pilot-scale tests to: 1) optimize the MAPHEX System configuration; 2) optimize the concentration of chemical amendment; 3 ) optimize the grade of diatomaceous earth in the final filtration step; and then to 4) perform a series of longer, sustained runs to measure $P$ removal efficiencies for swine manure and to estimate flow rates.

\section{MATERIALS AND METHODS MANURES TESTED}

For this study, manures were collected from four swine (S. domesticus) farms of varying herd sizes and production systems to represent manures from around the swine industry. Farm operations ranged from farrow-to-finish to finishing facilities with herds from 600-2200 hogs. The farrow-tofinish farms house and raise all stages of pig growth from breeding through finishing to a market weight of about $130 \mathrm{~kg}$. The finishing facilities are either contracted or privately managed and raise pigs (feeders) approximately 18$22 \mathrm{~kg}$ to full market weight. The sampling strategy was to obtain samples of various manure types, including: 1) agitated raw samples, 2) bottom of pit (high solids), and 3) unagitated liquor samples from the top third of the pit. In some cases, multiple samples were collected on a single farm.

A pump was used to collect the samples into large IBC plastic tanks (1041 L) for ease of transportation to the testing facility. Samples were stored outside until testing was complete. Some of the samples were frozen over the winter months and thawed in the spring for testing.

\section{0-Hog Finishing Operation (WAS)}

The MAPHEX System was used to treat manure from a large contracted 2200 hog finishing operation in Huntingdon County, Pennsylvania, where hogs are housed in a single large barn with a slotted floor. Hogs are fed primarily a soybean and corn-based diet with no phytase addition, and they typically raise three cycles of hogs each year. The manure collected in the under-barn pit is treated with Microbe-Lift Hog treatment (Ecological Laboratories, Inc., Island Park, N.Y.), a proprietary microbial culture and enzyme formulation that is reported to reduce crusting, solids buildup and odor. The treatment sample was collected in October 2018 at the end of a cycle of hogs from an exterior access to the pit at a depth of 1-1.2 $\mathrm{m}$. The pit was full at the time of collection and in the process of pumping and hauling for field application but was not agitated prior to collection.

\section{0-Hog Farrow-to-Finish Operation (PSU)}

Manure was collected from a medium sized research operation in Centre County, Pennsylvania. This farm has four barns including a breeding and gestation facility for 25 sows, a farrowing and nursery barn for young piglets $(\sim 200)$ and three finishing barns one of which was built based on the "Nebraska barn" engineering design. The breeding, farrowing, and two finishing barns have concrete floors and are scrapped daily to Y gutters at the end of the barns. The Y gutters are flushed to the main underground covered manure pit weekly. The Nebraska barn has a partially slotted floor and is mechanically scrapped two times per week to a small underground pit. This pit is pumped to the main pit every 23 weeks depending on age and size of hogs. All barns house 7 cycles a year. No manure additives are used at this facility. Hogs are fed primarily a soybean- and corn-based diet with no phytase addition. Facilities are washed down between cycles with a rotation of disinfectants. At this facility, four manure samples were collected and tested including: 1) an agitated raw manure sample from the farrow-to-finishing pit (PSU-MR); 2) an unagitated manure sample from the farrow-to-finishing pit (PSU-L); 3) an agitated manure sample from the finishing barn (PSU-FR); and, 4) an unagitated bottom sample from the finishing barn pit (PSU-FB). On samples from this farm only, an excessive amount of foam occurred during solids separation, chemical treatment, and filtration stages of the MAPHEX System. Due to this, full testing of these manures was only completed on the agitated (PSU-MR) and unagitated raw manure sample (PSU-L) from the farrow-to-finishing pit. The cause of the foaming is still being studied, but for these samples, the foaming could be controlled by defoamer addition.

\section{0-Hog Farrow-to-Finish Operation (HG)}

A manure sample was collected from an above-ground, open slurry store from a farrow-to-finish operation in central 
Pennsylvania. This privately owned operation houses 150 sows in the farrowing facility, 600 weaned piglets in the nursery, and 600 hogs in the finishing facility. Hogs are fed primarily a soybean- and corn-based diet with no phytase addition. All manure from these facilities are collected in under-barn pits, which are pumped to the main slurry store. No agitation is used in the slurry store and when pumped down, 1-1.2 m of settled solids remain. The sample was collected when the pit was full after a particularly rainy fall season, and thus the sample was dilute.

\section{0-Hog Finishing Operation (KT)}

This manure source is located in Northumberland County Pennsylvania. It is a finishing operation that grows $18 \mathrm{~kg}$ feeder pigs to a finished weight of $130 \mathrm{~kg}$. The barn houses 900 animals and will produce three groups per year. Phytase has been used in the feed at this operation. The barn has a slotted floor over a pit which is transferred to a large uncovered outside storage lagoon as needed. At this facility, three manure samples were collected and tested including; an agitated raw manure (KT-R) at the time of flushing from the barn, an unagitated manure sample (KT-L), and an unagitated manure sample from the bottom of the pit prior to flush from the barns (KT-B), that contained high solids that would not stay in suspension with agitation. The samples were collected at 1-1.5 $\mathrm{m}$ deep from the main uncovered manure pit.

\section{MAPHEX SYSTEM CONFIGURATION AND OPERATION}

The MAPHEX System, as used to treat dairy manure (fig. 1), consists of:

Stage A) liquid/solid separation using an auger (Neptune Enterprises, Richland Center, Wis.) or screw press (Boerger, Chanhassen, Minn.) to remove solids larger than $1 \mathrm{~mm}$;

Stage B) liquid/solid separation using a decanter centrifuge (Sharples P-3400, Alfa Laval, Lund, Sweden) to remove solids larger than about $30 \mu \mathrm{m}$;

Stage C) chemical treatment [typically $\mathrm{Fe}_{2}\left(\mathrm{SO}_{4}\right)_{3}$ ];

Stage D) final liquid/solid separation using an AutoVac $\mathbb{R}$ (ALAR Engineering Corporation, Mokena, Ill.) filtration unit.

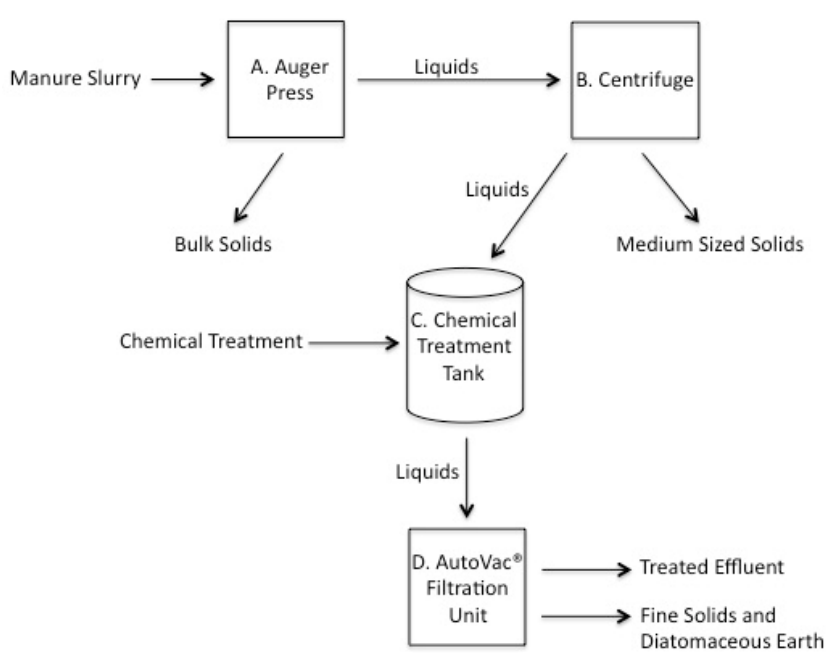

Figure 1. The full-scale MAPHEX System.
For this study on swine manure, the auger/screw press stage was not used and, for some experiments, the centrifuge was omitted as well. Swine manure, or effluent from the centrifuge, was batch treated with chemical amendment (discussed below) prior to being pumped to the pilot-scale AutoVac ${ }^{\circledR}$ unit $(A V-110)$. This unit uses a rotating drum under vacuum to filter effluent through a diatomaceous earth filter, while simultaneously employing a knife to cut off manure solids and diatomaceous earth (such that a clean surface is presented to the manure to be filtered) to remove fine solids and those solids created by the chemical treatment. Both the knife speed (movement towards the inside of the drum) and drum rotation speed are operator adjustable to achieve a desired level of dryness in the solids removed by the knife. In order to be consistent in our tests, we chose a knife speed of $6.4 \mu \mathrm{m} \mathrm{s}^{-1}$, adjusting drum speed from 2.6-3.7 rotations per minute such that the solids appeared dry on the surface before reaching the knife to be cut off the drum.

\section{Chemical TREaTMENT EXPERIMENTS}

Manure slurries were subjected to chemical treatment [either 15 or $30 \mathrm{~g} \mathrm{~L}^{-1} \mathrm{Fe}_{2}\left(\mathrm{SO}_{4}\right)_{3}$ ] to coagulate particles and transform Dissolved P (primarily orthophosphate) into a solid form that can be removed by the AutoVac ${ }^{\circledR}$ unit. They were then run on the AutoVac ${ }^{\circledR}$ unit using FA140 filtrate media (discussed in greater detail below) at a knife speed of $6.4 \mu \mathrm{m} \mathrm{s}^{-1}$, adjusting drum speed such that the solids appeared dry on the surface before reaching the knife to be cut off the drum. This treatment was performed in batch mode on thoroughly mixed subsamples. The $\mathrm{Fe}_{2}\left(\mathrm{SO}_{4}\right)_{3}$ was mixed into the manure effluent using a drill and paddle and defoamer (3.5-17.9 $\mathrm{ml} \mathrm{L}^{-1}$ of Foambuster 10, Helena Chemical Company, Collierville, Tenn.) was used to control foam buildup. We measured dissolved and Total P removal efficiency in order to determine which treatment concentration caused the AutoVac ${ }^{\circledR}$ unit to be most effective at removing $\mathrm{P}$ from the solution. We also noted the visual cleanliness of the filtrate material after solids were cut off by the knife, and the clarity of the final effluent.

\section{Diatomaceous Earth Grade Selection EXPERIMENTS}

Manure slurries were thoroughly mixed and subjected to batch chemical treatment with $15 \mathrm{~g} \mathrm{~L}^{-1} \mathrm{Fe}_{2}\left(\mathrm{SO}_{4}\right)_{3}$ and then run on the AutoVac ${ }^{\circledR}$ unit at a knife speed of $6.4 \mu \mathrm{m} \mathrm{s}^{-1}$, adjusting drum speed such that the solids appeared dry on the surface before reaching the knife to be cut off the drum. The AutoVac ${ }^{\circledR}$ unit had its drum coated with either FA120 (reported $0.7 \mu \mathrm{m}$ removal of particles, ALAR Engineering Corporation, Mokena, Ill.) or FA140 (reported $0.9 \mu \mathrm{m}$ removal of particles, ALAR Engineering Corporation, Mokena, Ill.) grades of diatomaceous earth and we tested for: 1) flow rate through the AutoVac ${ }^{\circledR}$ unit; 2) solids removal efficiency; 3) P removal efficiency; 4) clarity of the final effluent; and 5) visual cleanliness of the filtrate material after solids were cut off by the knife. 
SAMPle Collection/Preservation

AND LABORATORY ANALYSIS

Sample Collection and Preservation - A V Testing

An initial sample was taken of the raw or centrifuged swine manure from well-mixed totes to determine Total and Dissolved P. For the series of chemical optimization and diatomaceous earth grade selection tests, the manure slurry was run on the AutoVac $\AA$ unit for 10-30 min, and the entire run was physically averaged in a large-scale churn splitter (essentially a large-scale churn splitter, USGS 1998) that homogenized the entire production of the run. After optimizing the system for chemistry and diatomaceous earth grade, a series of longer (30-60 min), more controlled runs were performed. To test for variability during these runs, flow rate was measured multiple times, and multiple (with one exception) samples of effluent from the centrifuge and/or AutoVac $\AA$ unit were taken during the course of the runs. All samples were stored at $4^{\circ} \mathrm{C}$ until analyzed.

\section{EPA $3050 b$ P, Dissolved P, and Total Sediment Determination}

Samples were subjected to EPA 3050B extraction for Total $\mathrm{P}$ analysis. Briefly, manure slurries and solids were extracted with nitric and hydrochloric acids and hydrogen peroxide following a modified EPA Standard Method 3050B (Kimbrough and Wakakuwa, 1989). Samples were digested wet based on sample size containing approximately $0.5 \mathrm{~g}$ of solid material or $5 \mathrm{~mL}$ maximum. Following dilution to final volumes and filtration (Whatman No. 1), P analysis was then performed on all extracts using an inductively coupled optical emission spectrophotometer (ICP-OES, Varian). Dissolved $\mathrm{P}$ was determined by filtering samples through a $0.45 \mu \mathrm{m}$ filter (or through $0.2 \mu \mathrm{m}$ filter for the chemical treatment testing), and then analysis was performed using an inductively coupled optical emission spectrophotometer (ICP-OES, Varian) dry matter of raw manures and centrifuge solids were determined by oven drying at $110^{\circ} \mathrm{C}$ for $16 \mathrm{~h}$. Total sediment of AV effluents from DE grades were determined by gravimetric determination, with samples evaporated at $90^{\circ} \mathrm{C}$.

\section{Data Analysis}

Phosphorus removal efficiencies were determined using a mass balance approach comparing influent loads with observed loads in effluent liquids at each step of the manure treatment process. Means, standard errors, and aggregate Total $\mathrm{P}$ removed (i.e., the aggregate amount of $\mathrm{P}$ removed across different stages of the MAPHEX process) are reported.

\section{RESULTS AND DISCUSSION CONFIGURATION OF THE MAPHEX SYSTEM FOR SWINE MANURE}

As stated earlier, we had previously shown the full MAPHEX System (fig. 1) to be effective at treating dairy manure (Church et al., 2016, 2017, 2018). Swine manure however, has many different characteristics that led us to expect that a different configuration would be equally effective in recovering $\mathrm{P}$ while allowing a simpler and less expensive design. For example, compared to dairy manure, swine manure has: 1) lower total solids; 2) much lower bulk solids; and 3) more readily lends itself to liquid/solid separation. Because of these characteristics, swine manure tends to be of much lower viscosity. Also, because swine manure readily lends itself to liquid/solid separation (usually gravity separating on its own relatively quickly), treating only the manure liquor pumped from the top of a settling pond or pit is a viable option that greatly reduces the volume of manure in storage while removing most of the $\mathrm{P}$ from the effluent that would be spread on fields.

In testing, we found that the auger or screw press (Stage A) was not needed, and that, in cases when initial solids separation would be needed (e.g., following agitation of manure or when manure from the bottom of a lagoon were treated), it could be replaced with a less expensive gravity screen unit to remove hair and unintended larger debris. Furthermore, we found that since larger solids readily separate and sink to the bottom if swine manure is allowed to sit in a lagoon or pit, that even the centrifuge (Stage B) was not needed to treat the manure liquor pumped from the top. These findings show that a simpler and less expensive system design would be needed to treat raw agitated manure, and a much less expensive system would be effective at reducing lagoon storage volumes for farmers who chose to allow solids sludge to build up on the bottom of the lagoon and dispose of after a few decades.

\section{Chemical Treatment}

Another major characteristic of swine manure is that, compared to dairy manure, it typically contains as much as ten times the concentration of Dissolved $\mathrm{P}$ and higher water extractable P (Lui et al., 2018). We therefore anticipated that we would need a greater amount of chemical treatment than the $3.0 \mathrm{~g} \mathrm{~L}^{-1} \mathrm{Fe}_{2}\left(\mathrm{SO}_{4}\right)_{3}$ we found to be sufficient for dairy manure. We treated two different centrifuged swine manures with both ten (10X Treatment, $30.0 \mathrm{~g} \mathrm{~L}^{-1}$ ) and five (5X Treatment, $\left.15.0 \mathrm{~g} \mathrm{~L}^{-1}\right)$ times the amount of $\mathrm{Fe}_{2}\left(\mathrm{SO}_{4}\right)_{3}$ that we typically used for dairy manure treatment, and then ran the treated manures through the AutoVac ${ }^{\circledR}$ filtration unit (table 1).

Surprisingly, we found that while the $10 \mathrm{X}$ Treatment showed $40 \%$ and $37 \%$ removal of Dissolved $P$ and $41 \%$ and $70 \%$ removal of Total $\mathrm{P}$ for the $\mathrm{HG}$ and WAS centrifuged manures, respectively, the 5X Treatment showed 99\% removal of Dissolved P for both manures, and $96 \%$ and $100 \%$ removal of Total $\mathrm{P}$ for the $\mathrm{HG}$ and WAS centrifuged manures, respectively. We also observed that the $10 \mathrm{X}$ Treatment caused the final effluent to contain considerable colloidal iron oxyhydroxides, and it appeared that the diatomaceous earth left on the drum after the cutting knife also contained considerable iron oxyhydroxides, whereas neither of those observations were seen with the $5 \mathrm{X}$ Treatment. We therefore chose to use the $5 \mathrm{X}$ Treatment for all subsequent tests.

\section{Diatomaceous Earth Grade Choice}

As noted previously, swine manures (particularly if only the liquor rather than agitated or bottom sludges are run) tend to have lower concentrations of total solids, and bulk solids 
Table 1. Chemical treatment concentration tests.

\begin{tabular}{|c|c|c|c|c|c|c|c|c|}
\hline \multirow[b]{3}{*}{$\begin{array}{l}\text { Manure } \\
\text { Source }\end{array}$} & \multicolumn{4}{|c|}{$10 X\left(30 \mathrm{~g} \mathrm{~L}^{-1}\right)$} & \multicolumn{4}{|c|}{$5 \mathrm{X}\left(15 \mathrm{~g} \mathrm{~L}^{-1}\right)$} \\
\hline & \multirow[b]{2}{*}{$\begin{array}{l}\text { Dissolved } \mathrm{P}^{[\mathrm{a}]} \\
\left(\mathrm{mg} \mathrm{L}^{-1}\right)\end{array}$} & \multirow{2}{*}{$\begin{array}{c}\text { Dissolved P } \\
\text { Removed } \\
(\%)\end{array}$} & \multirow[b]{2}{*}{$\begin{array}{c}\text { Total P } \\
\left(\mathrm{mg} \mathrm{kg}^{-1}\right)\end{array}$} & \multirow{2}{*}{$\begin{array}{c}\text { Total P } \\
\text { Removed } \\
(\%)\end{array}$} & \multicolumn{3}{|c|}{ Dissolved P } & \multirow{2}{*}{$\begin{array}{c}\text { Total P } \\
\text { Removec } \\
(\%)\end{array}$} \\
\hline & & & & & $\begin{array}{l}\text { Dissolved } \mathrm{P}^{[\mathrm{a}]} \\
\quad\left(\mathrm{mg} \mathrm{L}^{-1}\right)\end{array}$ & $\begin{array}{c}\text { Removed } \\
(\%)\end{array}$ & $\begin{array}{c}\text { Total P } \\
\left(\mathrm{mg} \mathrm{kg}^{-1}\right)\end{array}$ & \\
\hline HG Centrifuged & 55.5 & & 72.4 & & 39.8 & & 82.8 & \\
\hline Treated & 37.0 & 40.4 & 43.1 & 40.5 & 0.7 & 98.5 & 3.4 & 95.9 \\
\hline 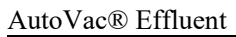 & 33.1 & & & & 0.6 & & & \\
\hline WAS Centrifuged & 47.2 & & 55.3 & & 78.4 & & 98.9 & \\
\hline Treated & 11.1 & 37.2 & 16.4 & 70.4 & 0.4 & 99.2 & 0.3 & 99.7 \\
\hline AutoVac $\AA$ Effluent & 7.0 & & & & 0.6 & & & \\
\hline
\end{tabular}

[a] Filtered through $0.2 \mu \mathrm{m}$ filter.

concentrations typically are very low. Therefore, while we had previously found the FA-140 $(0.9 \mu \mathrm{m}$ pore size $)$ grade

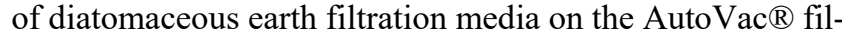
tration unit to be an effective choice for a broad range of dairy manures (Church et al., 2016, 2017, 2018), we chose to test a finer grade of filtrate, FA-120 $(0.7 \mu \mathrm{m}$ pore size $)$, on a broad range of swine manures as well (table 2).

We saw little difference between the two grades in flow rates, total sediment, or in P removal between the two grades for any of the manures tested. There was an observational difference however. In most cases, it appeared that the diatomaceous earth left on the drum after the cutting knife was much cleaner with the FA-120 than with the FA-140, indicating that manure solids were likely entering pore spaces in the filtrate rather than being held near the surface. While we saw no evidence that this affected the flow rates in the short test runs since we saw little difference in flow rates between the two grades, we chose to use the finer FA-120 for longer term runs to avoid possible issues with filtrate clogging.

\section{Phosphorus Removal}

\section{Centrifuge Plus Autovac ${ }^{\circledR}$ System Configuration}

For manures which had considerable solids (either from agitation or because sludges were pumped from the bottom) we chose to use a configuration that consisted of 1) liquid/solid separation by the decanter centrifuge, 2) chemical treatment, and 3) final liquid/solid separation by the AutoVac ${ }^{\circledR}$ filtration unit. Aggregate $\mathrm{P}$ removal by this system ranged from $96 \%$ to $100 \%$ removal for all farms tested (table 3 ), and solids removed by both the centrifuge and AutoVac $\AA$ were stackable, containing between $70 \%$ and $75 \%$ moisture. Phosphorus removal by the centrifuge ranged from $42 \%$ to $86 \%$ of Total $P$, while the AutoVac ${ }^{\circledR}$ filtration unit was effective in removing nearly all $\mathrm{P}$ remaining in the centrifuge effluent after it was treated with $15.0 \mathrm{~g} \mathrm{~L}^{-1} \mathrm{Fe}_{2}\left(\mathrm{SO}_{4}\right)_{3}$. The flow rates observed for swine manure (with the exception of the manure sludge (KT-B) from the bottom of the lagoon, which was equal to the typical average for dairy manure) were 1.5 to 5 times higher for swine manure than for dairy manure run under similar conditions, suggesting that costs per liter treated could be much lower for swine manure.

\section{AutoVac $\circledast$ Only System Configuration}

For manures which were essentially manure liquors due to them being pumped from the top of the lagoon or storage pit, leaving behind the sludge in the bottom, we chose to use a configuration that consisted only of 1) chemical treatment, and 2) final liquid/solid separation by the AutoVac $\AA$ filtration unit. P removal for this system ranged from 99 to 100 percent removal for all farms tested (table 4), and solids removed by both the centrifuge and AutoVac $\AA$ were stackable, containing between $70 \%$ and $75 \%$ moisture. Phosphorus removal by the centrifuge ranged from $42 \%$ to $86 \%$ of Total $P$, while the AutoVac ${ }^{\circledR}$ filtration unit was effective in removing nearly all $\mathrm{P}$ remaining in the centrifuge effluent after it was treated with $15.0 \mathrm{~g} \mathrm{~L}^{-1} \mathrm{Fe}_{2}\left(\mathrm{SO}_{4}\right)_{3}$. Again, flow rates observed for swine manure were about 1.5 to 5 times higher than for dairy manure run under similar conditions, suggesting that swine manure could be treated for a lower cost.

Table 2. Diatomaceous earth grade selection.

\begin{tabular}{|c|c|c|c|c|c|c|c|}
\hline & & \multicolumn{3}{|c|}{ FA-140 } & \multicolumn{3}{|c|}{ FA-120 } \\
\hline \multirow{2}{*}{\multicolumn{2}{|c|}{$\begin{array}{r}\text { Manure Source } \\
\end{array}$}} & $\begin{array}{c}\text { AutoVac Flow } \\
\text { Mean (StdErr) n } \\
\left(\mathrm{L} \min ^{-1}\right)\end{array}$ & $\begin{array}{c}\text { Total } \\
\text { Sediment } \\
\left(\mathrm{g} \mathrm{L}^{-1}\right)\end{array}$ & $\begin{array}{c}\text { Total P } \\
\text { Removed } \\
(\%)\end{array}$ & 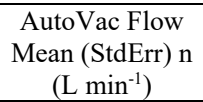 & $\begin{array}{c}\text { Total } \\
\text { Sediment } \\
\left(\mathrm{g} \mathrm{L}^{-1}\right)\end{array}$ & $\begin{array}{c}\text { Total P } \\
\text { Removec } \\
(\%)\end{array}$ \\
\hline & \multicolumn{7}{|c|}{ Agitated Manure } \\
\hline \multirow{2}{*}{ KT-R } & Cent + AV® & $1.15(0.05) 23$ & 13.6 & 99.6 & $1.10(0.03) 26$ & 16.5 & 99.7 \\
\hline & AutoVac $\AA$ only & $1.22(0.05) 17$ & 12.3 & 98.5 & $1.51(0.03) 37$ & 11.4 & 98.9 \\
\hline \multirow{2}{*}{ PSU-FR } & Cent + AV® & NA & NA & NA & $0.23(0.02) 17$ & 6.4 & 99.8 \\
\hline & 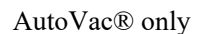 & NA & NA & NA & NA & NA & NA \\
\hline \multirow{2}{*}{ PSU-L } & Cent $+\mathrm{AV} \circledast$ & $2.06(0.07) 26$ & 13.0 & 100.0 & $2.49(0.05) 21$ & 12.9 & 100.0 \\
\hline & AutoVac $\AA$ only & NA & NA & NA & NA & NA & NA \\
\hline \multicolumn{8}{|c|}{$\overline{\text { Bottom Sludge }}$} \\
\hline \multirow{2}{*}{ KT-B } & Cent + AV® & $0.73(0.03) 18$ & 11.8 & 99.9 & $0.77(0.02) 25$ & 12.8 & 99.9 \\
\hline & AutoVac $(\AA$ only & NA & NA & NA & NA & NA & NA \\
\hline \multicolumn{8}{|c|}{ Manure Liquor } \\
\hline \multirow{2}{*}{ HG } & Cent + AV® & $3.84(0.05) 21$ & 9.9 & 96.9 & $4.02(0.05) 19$ & 10.1 & 96.3 \\
\hline & AutoVac $₫$ only & $3.55(0.05) 11$ & 8.94 & 97.3 & $3.67(0.06) 10$ & 8.1 & 99.9 \\
\hline \multirow{2}{*}{ WAS } & Cent + AV® & $2.54(0.03) 12$ & 13.2 & 99.7 & $3.03(0.06) 10$ & 13.6 & 99.1 \\
\hline & AutoVac $\AA$ only & $2.30(0.03) 12$ & 12.8 & 98.5 & $2.27(0.03) 18$ & 11.4 & 98.4 \\
\hline \multirow{2}{*}{ KT-L } & Cent $+\mathrm{AV} \otimes$ & NA & NA & NA & NA & NA & NA \\
\hline & 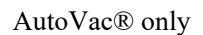 & $1.63(0.08) 18$ & 12.3 & 96.4 & $1.74(0.05) 22$ & 12.67 & 99.6 \\
\hline
\end{tabular}


Table 3. Phosphorus Removal by Centrifuge plus AutoVac ${ }^{\circledR}$ Configuration.

\begin{tabular}{|c|c|c|c|c|c|}
\hline \multicolumn{2}{|c|}{ Manure Source } & $\begin{array}{c}\text { AutoVac Flow } \\
\text { Mean (StdErr) n } \\
\left(\mathrm{L} \min ^{-1}\right)\end{array}$ & $\begin{array}{c}\text { Total P } \\
\text { Mean }(\text { StdErr }) \mathrm{n} \\
\left(\mathrm{mg} \mathrm{kg}^{-1}\right)\end{array}$ & $\begin{array}{c}\text { Total P } \\
\text { Removed } \\
(\%)\end{array}$ & $\begin{array}{c}\text { Aggregate Total } \\
\text { P Removed } \\
(\%)\end{array}$ \\
\hline \multicolumn{6}{|c|}{ Agitated Manure } \\
\hline \multirow{3}{*}{ KT-R } & Raw & \multirow{3}{*}{$1.1(0.03) 26$} & $983(80) 3$ & & \multirow{3}{*}{99.7} \\
\hline & Centrifuge & & $137(18) 7$ & 86 & \\
\hline & AutoVac $\mathbb{R}$ & & $3.1(0.3) 8$ & 14 & \\
\hline \multirow{3}{*}{ PSU-L } & Raw & \multirow{3}{*}{$2.5(0.05) 21$} & $907(\mathrm{NA}) 1$ & & \multirow{3}{*}{100.0} \\
\hline & Centrifuge & & $145(11) 4$ & 85 & \\
\hline & AutoVac $\mathbb{R}$ & & $0.2(0.05) 6$ & 16 & \\
\hline \multicolumn{6}{|l|}{ Bottom Sludge } \\
\hline \multirow{3}{*}{ KT-B } & Raw & \multirow{3}{*}{$0.7(0.04) 20$} & $3047(94) 2$ & & \multirow{3}{*}{99.9} \\
\hline & Centrifuge & & $473(76) 2$ & 84 & \\
\hline & 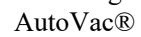 & & $2.56(0.12) 8$ & 15 & \\
\hline \multicolumn{6}{|l|}{ Manure Liquor } \\
\hline \multirow{3}{*}{$\mathrm{HG}$} & Raw & \multirow{3}{*}{$4.0(0.05) 19$} & $100.5(42) 2$ & & \multirow{3}{*}{96.3} \\
\hline & Centrifuge & & $64(1) 3$ & 42 & \\
\hline & 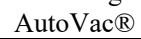 & & $2.9(0.24) 8$ & 54 & \\
\hline \multirow{3}{*}{ WAS } & Raw & \multirow{3}{*}{$2.5(0.03) 24$} & $109(19) 2$ & & \multirow{3}{*}{99.7} \\
\hline & Centrifuge & & $63(3) 2$ & 43 & \\
\hline & AutoVac $\AA$ & & $0.47(0.04) 7$ & 57 & \\
\hline
\end{tabular}

\section{IMPLICATIONS AND ECONOMICS}

This pilot-scale study shows that the MAPHEX System can remove greater than $96 \%$ of the phosphorus from a wide range of swine manures and strongly suggests that, once scaled up, the essentially P free effluent could be beneficially used for fertigation without further loading the receiving soils with $\mathrm{P}$. This scaling up has the potential to reduce storage volumes to allow for mitigation of overflow problems during large storms. Furthermore, a simpler configuration means that the capital equipment costs for treating swine manure would be lower than for treating dairy manure.

The solids removed by the MAPHEX System also have beneficial uses. The centrifuge and AutoVac ${ }^{\circledR}$ solids contain high amounts of $P$. This compact form allows for the potential beneficial use of the centrifuge solids by; 1) cutting fuel costs considerably, allowing them to economically transport phosphorus to distant fields, 2) being sold to organic farmers or the nursery and mushroom industries, or composted and sold in garden centers, or 3) used as a feedstock for energy generation, which also concentrates the phosphorus into a very compact, residual ash that can serve as a phosphorus and trace element fertilizer.

The most economical use for the AutoVac ${ }^{\circledR}$ solids on the other hand, is likely to involve recovery and reuse of the di-

Table 4. Phosphorus removal by AutoVac ${ }^{\circledR}$ only configuration.

\begin{tabular}{|c|c|c|c|c|}
\hline \multicolumn{2}{|c|}{$\begin{array}{c}\text { Manure } \\
\text { Source }\end{array}$} & $\begin{array}{c}\text { AutoVac Flow } \\
\text { Mean(StdErr)n } \\
1 \mathrm{~min}^{-1} \\
\end{array}$ & $\begin{array}{c}\text { Total P } \\
\text { Mean }(\text { StdErr }) n \\
\left(\mathrm{mg} \mathrm{kg}^{-1}\right)\end{array}$ & $\begin{array}{c}\text { Total P } \\
\text { Removed } \\
(\%) \\
\end{array}$ \\
\hline \multicolumn{5}{|c|}{ Agitated Manure } \\
\hline KT-R & $\begin{array}{c}\text { Raw } \\
\text { AutoVac } \mathbb{}\end{array}$ & $1.0(0.03) 32$ & $\begin{array}{l}983(80) 3 \\
3.1(0.3) 8 \\
\end{array}$ & 99.4 \\
\hline \multicolumn{5}{|c|}{ Manure Liquor } \\
\hline HG & $\begin{array}{c}\text { Raw } \\
\text { AutoVac } \mathbb{R}\end{array}$ & $4.2(0.15) 18$ & $\begin{array}{l}101(42) 2 \\
1.9 \text { (NA)1 }\end{array}$ & 99.9 \\
\hline WAS & $\begin{array}{c}\text { Raw } \\
\text { AutoVac } \mathbb{R}\end{array}$ & $2.5(0.04) 18$ & $\begin{array}{c}109(19) 2 \\
0.35(0.03) 5\end{array}$ & 99.7 \\
\hline KT-L & $\begin{array}{c}\text { Raw } \\
\text { AutoVac } \mathbb{R}\end{array}$ & $1.7(0.04) 32$ & $\begin{array}{l}397(16) 4 \\
0.5(0.1) 5 \\
\end{array}$ & 99.9 \\
\hline PSU-MR & $\begin{array}{c}\text { Raw } \\
\text { AutoVac } \mathbb{R}\end{array}$ & $3.3(0.05) 22$ & $\begin{array}{l}296 \text { (NA) } 1 \\
0.2(0.01) 6\end{array}$ & 99.9 \\
\hline
\end{tabular}

atomaceous earth filtrate material. We have recently reported on methodologies to do this which essentially involve incineration, directly reusing the filtrate twice, and then regenerating it to an original flow rate by acid washing (Church et al., 2019). This recovery and reuse of filtrate material, rather than it being a daily consumable expense, reduces the cost per liter of manure treated by about a factor of 5 .

Based on the results of this study and the wide range of flow rates observed (tables 3 and 4), we project that a modified version of our current full-scale MAPHEX System would be capable of treating approximately $35,000 \mathrm{~L}$ of bottom sludge, 51,000-130,000 L of agitated swine manure, or $88,000-218,000 \mathrm{~L}$ of swine manure liquor per day. Capital equipment costs for this modified system, if built in place on a farm, would range from about $\$ 250,000$ for a system that included a centrifuge, to $\$ 150,000$ for the AutoVac $\AA$ only version. Treatment cost per liter, based on this study would range from about 0.8 cents/L for bottom sludge, 0.2-0.5 cents/L of agitated swine manure, or $0.1-0.32$ cents/L of swine manure liquor.

\section{ACKNOWLEDGEMENTS}

This work presented here is covered by US Patent 9,790.110B2, and U.S. Patent Application Serial No. 62/548,231, filed 22 August 2019. Special thanks are extended to David Otto (retired), who contributed significantly to the design of both the original prototype and full-scale MAPHEX Systems.

\section{REFERENCES}

Chastain, J. P., \& Henry, S. (2003). Management of lagoons and storage structures for swine manure. 1-31. Clemson University. Retrieved from https://www.clemson.edu/extension/camm/manuals/swine/sch4 03.pdf

Church, C. D., Hristov, A. N., Bryant, R. B., \& Kleinman, P. J. A. (2017). Processes and treatment systems for treating high phosphorus containing fluids. U.S. Patent No. 9,790.110B2. 
Church, C. D., Hristov, A. N., Bryant, R. B., Fishel, S. K., \& Kleinman, P. J. A. (2016). A novel treatment system to remove phosphorus from liquid manure. Appl. Eng. Agric., 32(1), 103112. https://doi.org/10.13031/aea.32.10999

Church, C. D., Hristov, A. N., Kleinman, P. J. A., Fishel, S. K., Reiner, M. R., \& Bryant, R. B. (2018). Versatility of the MAnure PHosphorus EXtraction (MAPHEX) system in removing phosphorus, odor, microbes, and alkalinity from dairy manures: A four-farm case study. Appl. Eng. Agric., 34(3), 567572. https://doi.org/10.13031/aea.12632

Church, C. D., Hristov, A., Bryant, R. B., \& Kleinman, P. J. A. (2019). Methods for rejuvenation and recovery of filtration media. USDA Docket No. 129.17. U.S. Patent Application Serial No. 62/548,231.

Fleishman, G. (2018). Farmers are racing to drain their massive hog manure ponds, before Hurricane Florence washes them away. Fortune. Retrieved from https://fortune.com/2018/09/12/hurricane-florence-hog-manureponds-lagoons-overflow/

Kimbrough, D. E., \& Wakakuwa, J. R. (1989). Acid digestion for sediments, sludges, soils, and solid wastes. A proposed alternative to EPA SW 846 Method 3050. Environ. Sci. Technol., 23(7), 898-900. https://doi.org/10.1021/es00065a021

Kleinman, P., Blunk, K. S., Bryant, R., Saporito, L., Beegle, D., Czymmek, K.,... Smith, M. (2012). Managing manure for sustainable livestock production in the Chesapeake Bay Watershed. JSWC, 67(2), 54A-61A. https://doi.org/10.2489/jswc.67.2.54A

Liu, J., Spargo, J. T., Kleinman, P. J. A., Meinen, R., Moore Jr., P. A., \& Beegle, D. B. (2018). Water-extractable phosphorus in animal manure and manure compost: Quantities, characteristics, and temporal changes. JEQ, 47(3), 471-479. https://doi.org/10.2134/jeq2017.12.0467
Pagliari, P. H., \& Laboski, C. A. (2012). Investigation of the inorganic and organic phosphorus forms in animal manure. $J E Q$, 41(3), 901-910. https://doi.org/10.2134/jeq2011.0451

Pagliari, P. H., \& Laboski, C. A. (2013). Dairy manure treatment effects on manure phosphorus fractionation and changes in soil test phosphorus. Biol. Fertility Soils, 49(8), 987-999. https://doi.org/10.1007/s00374-013-0798-2

Pierre-Louis, K. (2018). Lagoons of pig waste are overflowing after Florence. Yes, That's as nasty as it sounds. New York Times. Retrieved from https://www.nytimes.com/2018/09/19/climate/florence-hogfarms.html

Schlanger, Z. (2018). Hog manure is escaping from 30 waste lagoons in North Carolina. Quartz. Retrieved from https://qz.com/1394435/hog-manure-is-escaping-from-13lagoons-in-north-carolina-after-florence/

Sharpley, A. N., Chapra, S. C., Wedepohl, R., Sims, J. T., Daniel, T. C., \& Reddy, K. R. (1994). Managing agricultural phosphorus for protection of surface waters: Issues and options. JEQ, 23(3), 437-451. https://doi.org/10.2134/jeq1994.00472425002300030006x

USGS. (1998). U.S. Geological Survey Book 9. Ch. A2, Section 2.2. In National field manual for the collection of water-quality data (pp. 45-48.). USGS.

Vansickle, J. (1999). Managing lagoons. National Hog Farmer. August 15. Retrieved from https://www.nationalhogfarmer.com/mag/farming_managing_la goons 